\title{
Quantification of Climate Changes and Human Activities That Impact Runoff in the Taihu Lake Basin, China
}

\author{
Dingzhi Peng, ${ }^{1}$ Linghua Qiu, ${ }^{2}$ Jing Fang, ${ }^{1}$ and Zhongyuan Zhang1 \\ ${ }^{1}$ College of Water Sciences, Beijing Normal University, Beijing 100875, China \\ ${ }^{2}$ Department of Civil Engineering, University of Hong Kong, Pokfulam, Hong Kong \\ Correspondence should be addressed to Dingzhi Peng; dzpeng@bnu.edu.cn
}

Received 15 July 2015; Revised 29 December 2015; Accepted 17 January 2016

Academic Editor: Hua Fan

Copyright (c) 2016 Dingzhi Peng et al. This is an open access article distributed under the Creative Commons Attribution License, which permits unrestricted use, distribution, and reproduction in any medium, provided the original work is properly cited.

\begin{abstract}
Although a fragile climate region, the Taihu Lake Basin is among the most developed regions in China and is subjected to intense anthropogenic interference. In this basin, water resources encounter major challenges (e.g., floods, typhoons, and water pollution). In this study, the impacts of climate changes and human activities on hydrological processes were estimated to aid water resource management in developed regions in China. The Mann-Kendall test and cumulative anomaly curve were applied to detect the turning points in the runoff series. The year of 1982 divides the study period (1956 2008) into a baseline period (1956 1981) and a modified period (1982 2008). The double mass curve method and the hydrological sensitivity method based on the Budyko framework were applied to quantitatively attribute the runoff variation to climate changes and human activities. The results demonstrated that human activities are the dominant driving force of runoff variations in the basin, with a contribution of $83 \sim 89 \%$; climate changes contributed to $11 \sim 17 \%$ of the variations. Moreover, the subregions of the basin indicated that humans severely disturbed the runoff variation, with contributions as high as 95 97\%.
\end{abstract}

\section{Introduction}

Extreme hydrological events, such as floods and droughts, occur frequently $[1,2]$. Most hydrological disturbances in basins are due to climatic and anthropogenic factors. Regional climate changes mainly influence precipitation and evapotranspiration, leading to an increase or decrease in regional water resources. Under climate change, complex hydrological uncertainties enhance the risk of disaster [3]. With rapid social and economic development, the intensity of human activities is increasing in most regions and is altering hydrological processes [4-7]. The dual impacts of climate changes and human activities alter the hydrological cycle and introduce water issues. There are many studies that attempt to separate the causes and effects of climate changes and human effects $[8,9]$. In some basins, climate changes play a key role in hydrological variations [10], while human activities dominate in the Red River Basin [11] and the Reno River catchment [12]. Actually, the effects of climate changes and human activities interact, but most research simply assumes that the factors are independent.
As a typical region that experiences climatic impacts and intense human interference, the Taihu Lake Basin was chosen as a study case. Climate factors, such as El Niño-Southern Oscillation (ENSO) and the East Asian monsoon, lead to a fluctuating climate in the basin [13]. Considering the strong urbanization, human activities also increase the flood risk [14]. Because of the rapid social and economic development, the demand on water resources is increasing. Therefore, attributing hydrological modifications to these driving forces will have practical significance for the sustainable management of water resources. In this study, the hydrological changes based on trends and turning points were revealed in the Taihu Lake Basin. The impacts of climate changes and human activities on hydrological processes were quantified.

\section{Study Area and Materials}

The Taihu Lake Basin (Figure 1), with an area of $36895 \mathrm{~km}^{2}$, is located in the core region of the Yangtze River Delta. The basin has a typical subtropical monsoon climate. The water 


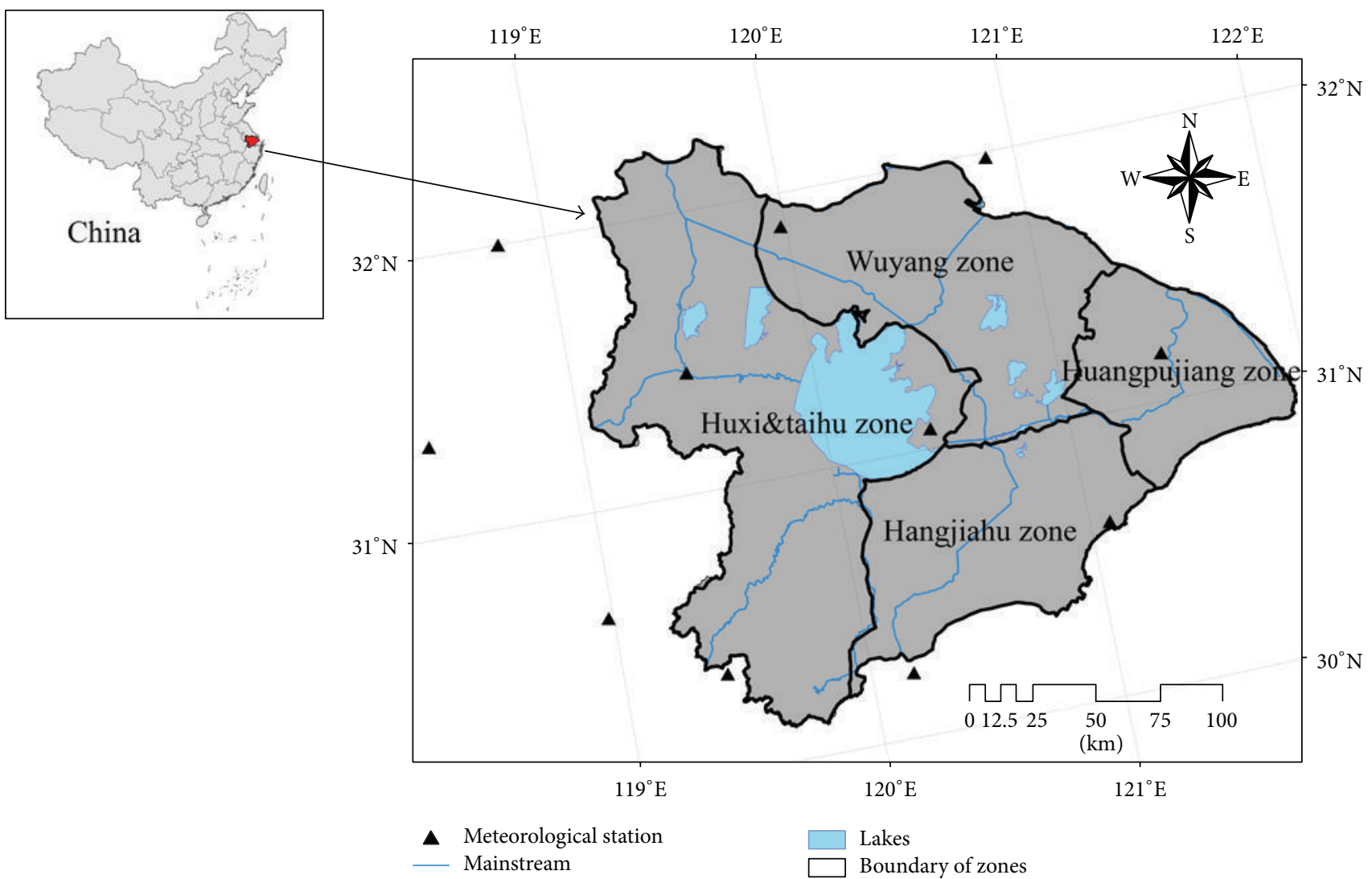

Figure 1: Taihu Lake Basin.

resource carrying capacity is quite low under climate changes. Moreover, the basin is one of the most developed areas in China. Many artificial river systems and hydraulic projects have been constructed. The underlying surface of the basin has been remarkably altered by human activities.

The annual mean precipitation of the Taihu Lake Basin is approximately $1200 \mathrm{~mm}$. However, the rainfall is concentrated in the flood season (from May to September). The annual mean runoff is nearly $430 \mathrm{~mm}$. In this study, the Taihu Lake Basin was divided into four zones (the administrative units of the Taihu Basin Authority, Ministry of Water Resources, China): the Wuyang Zone (WYZ), the Huxi and Taihu Zone (HTZ), the Hangjiahu Zone (HJHZ), and the Huangpujiang Zone (HPJZ). The hydrological characteristics of the four zones are listed in Table 1 . The daily precipitation, temperature, humidity, wind speed, and sunshine duration of 11 meteorological stations (see Figure 1) in the basin from 1956 to 2008 were collected from the China Meteorological Data Sharing Service System (http://data.cma.cn/). The daily potential evapotranspiration was estimated by the PenmanMonteith method [15] based on the meteorological data mentioned above. The annual precipitation and potential evapotranspiration were calculated and then interpolated by the inverse distance weighted method in each zone and the entire basin. The annual runoff of the basin and the four zones during 1956 2008 was provided by the Taihu Basin Authority, Ministry of Water Resources, China, respectively.

\section{Methods}

3.1. Trend and Turning Point Analysis. The cumulative departure curve was used to analyze the trends in the hydrological time series and to detect the preliminary turning points [13]. Then, the Mann-Kendall method [16-18] was employed to verify the turning points. The turning point was applied to divide the data series into two periods: the baseline period and the modified period. In the baseline period, the status or condition of the basin is assumed natural, without significant human interference (i.e., the reference period for the modified period). In contrast, human activities in the modified period are very apparent.

The departures of the cumulative departure curve are measured as follows [13]:

$$
\mathrm{De}_{i}=x_{i}-\bar{x},
$$

where $x$ is the time series. The extreme values of the cumulative departure curves are probably the turning points.

The MK method $[16,17]$ has been widely used to detect the trends and turning points of time series [18]. For an independent time series $\left(x_{1}, x_{2}, \ldots, x_{n}\right), S_{k}$ is established:

$$
S_{k}=\sum_{i=1}^{k} r_{i},
$$

where $k=2, \ldots, n$. In the equation, two observations are $i$ and $j(j=1,2, \ldots, i)$. If $x_{i}>x_{j}$, then $r_{i}=1$; if $x_{i}=x_{j}$, then 
TABLE 1: Hydrological characteristics of the Taihu Lake Basin and its zones during 1956 2008.

\begin{tabular}{lccc}
\hline Zone & $\begin{array}{c}\text { Annual runoff } \\
(\mathrm{mm})\end{array}$ & $\begin{array}{c}\text { Annual precipitation } \\
(\mathrm{mm})\end{array}$ & $\begin{array}{c}\text { Annual potential } \\
\text { evapotranspiration } \\
(\mathrm{mm})\end{array}$ \\
\hline Hangjiahu Zone & 451.7 & 1238.8 & 868.0 \\
Huangpujiang Zone & 395.2 & 1164.9 & 890.7 \\
Wuyang Zone & 373.0 & 1133.9 & 881.6 \\
Huxi and Taihu Zone & 463.8 & 1226.6 & 856.3 \\
Taihu Basin & 429.7 & 1199.5 & 870.3 \\
\hline
\end{tabular}

$r_{i}=0$; and if $x_{i}<x_{j}$, then $r_{i}=-1$. The statistical variable $U F_{k}$ has a standard normal distribution:

$$
U F_{k}=\frac{S_{k}-\overline{S_{k}}}{\sqrt{\operatorname{Var}\left(S_{k}\right)}}
$$

where $U F_{1}=0 ; \operatorname{Var}\left(S_{k}\right)$ and $\overline{S_{k}}$ are the variance and mean, respectively, of $S_{k}$. If the time series have the same continuous distribution, then

$$
\begin{aligned}
\overline{S_{k}} & =\frac{n(n+1)}{4}, \\
\operatorname{Var}\left(S_{k}\right) & =\frac{n(n-1)(2 n-5)}{18} .
\end{aligned}
$$

If $\left|U F_{k}\right|>\alpha$ for a given significance level $\alpha$, then the statistical series exhibits an obvious trend. Then, the process was repeated by the inverse time series $\left(x_{n}, \ldots, x_{2}, x_{1}\right)$ with $U B_{k}=-U F_{k}(k=n, n-1, \ldots, 1)$ and $U B_{1}=0$. Finally, the intersection of the two graphs $\left(U F_{k}, U B_{k}\right)$ is considered the turning point if it is within the critical lines.

3.2. Double Mass Curve Method. The runoff variation was attributed to impacts of both climate changes and human activities. The total runoff variation was calculated as follows:

$$
\Delta Q^{\text {tot }}=\Delta Q^{\text {human }}+\Delta Q^{\text {clim }},
$$

where $\Delta Q^{\text {clim }}$ and $\Delta Q^{\text {human }}$ are the runoff variation induced by climate changes and human activities, respectively. $\Delta Q^{\text {tot }}$ is the total runoff variation, which could also be calculated as follows:

$$
\Delta Q^{\text {tot }}=\overline{Q_{2}}-\overline{Q_{1}}
$$

where $\bar{Q}$ is the annual mean runoff. Subscripts 1 and 2 indicate the baseline period and modified period, respectively. Then, the contributions of climate changes and human activities to runoff variations could be estimated by

$$
\begin{gathered}
c^{\text {human }}=\frac{\Delta Q^{\text {human }}}{\Delta Q^{\text {tot }}}, \\
c^{\text {clim }}=\frac{\Delta Q^{\text {clim }}}{\Delta Q^{\text {tot }}},
\end{gathered}
$$

where $c^{\text {clim }}$ and $c^{\text {human }}$ represent the contribution of climate changes and human activities, respectively.
The double mass curve method [19] employs linear regression analysis of hydrological time series. The relationship between the cumulative runoff and cumulative precipitation in the baseline period is analyzed by

$$
\sum Q=k \sum P+b
$$

where $Q$ and $P$ are the runoff and precipitation, respectively. $k$ and $b$ are two parameters. Then, the regression equation is used to simulate the runoff in the modified period. Since the climate factor, precipitation, is the same for both the simulated and measured runoff, which eliminates the influence of climate changes, the difference between the mean simulated and measured runoff is the runoff variation induced by human activities:

$$
\Delta Q^{\text {human }}=\overline{Q_{2}^{\prime}}-\overline{Q_{2}},
$$

where $\overline{Q^{\prime}}$ is the annual mean simulated runoff. Then, the runoff variation induced by climate change is the difference between the total runoff variation and the runoff variation induced by human activities.

3.3. Hydrological Sensitivity Method Based on the Budyko Framework. The hydrological sensitivity method could be applied to estimate the impact of climate changes on hydrological processes based on the water balance $[20,21]$ :

$$
P=E+Q+\Delta S
$$

where $E$ is the evapotranspiration and $\Delta S$ is the variation in the water storage in the basin, which can be neglected for 5 10 years. Then, (10) could be transformed based on the relationship between evapotranspiration and potential evapotranspiration [22]:

$$
\frac{Q}{P}=1-\frac{E_{0} / P}{\left(1+\left(E_{0} / P\right)^{n}\right)^{1 / n}}=1-\frac{x}{\left(1+x^{n}\right)^{1 / n}},
$$

where $E_{0}$ is the potential evapotranspiration and $n$ is a landscape parameter; $x$ indicates the dryness index, that is, $E_{0} / P$. Then, the runoff variation induced by the climate changes could be calculated as follows [23]:

$$
\Delta Q^{\text {clim }}=\beta \Delta P+\gamma \Delta E_{0},
$$

where $\Delta P$ and $\Delta E_{0}$ are the changes in the precipitation and potential evapotranspiration, respectively; $\beta$ and $\gamma$ are 
the sensitivity coefficient of runoff to precipitation and potential evapotranspiration, respectively:

$$
\begin{aligned}
& \beta=1-\frac{x^{n+1}}{\left(1+x^{n}\right)^{1 / n+1}}, \\
& \gamma=-\frac{1}{\left(1+x^{n}\right)^{1 / n+1}} .
\end{aligned}
$$

Similarly, for the hydrological sensitivity method, the runoff variation induced by human activities is the difference between the total runoff variation and the runoff variation induced by climate change.

\section{Results and Discussion}

4.1. Hydrological Regimes. First, precipitation and runoff data in the Taihu Lake Basin were analyzed. In Figure 2(a), the cumulative departure curve of the precipitation tended to decrease until 1979 and then increased. Therefore, 1979 could be the turning point for precipitation. Then, the MannKendall test for precipitation showed a turning point in 1979 and verified the performance of the cumulative departure curve (Figure 2(b)). Similarly, the cumulative departure curve and the Mann-Kendall test of runoff both illustrated the turning point for runoff in 1982 (Figure 3).

The inconsistency in the turning points for precipitation and runoff could be attributed to both climate changes and human activities. Here, the turning point of runoff divided the time series into the baseline period (1956 1981) and the modified period (1982 2008). In fact, the open policy of China exerted at the end of 1970s accelerated social and economic development, particularly in the Yangtze River Delta. Intense human activities began in the early 1980s in the most basins of China, including the Taihu Lake Basin. Moreover, the river system changed significantly, and the number of lakes decreased after the 1980s. The land use/cover distinctly changed in the 1980s due to social and economic development [24]. Thus, the turning point of 1982 was reasonable.

4.2. Assessment of the Causes of the Runoff Variation. The runoff, precipitation, and potential evapotranspiration increased by $46.7 \mathrm{~mm}, 51.4 \mathrm{~mm}$, and $106.9 \mathrm{~mm}$ in the modified period compared with the baseline period. In Figure 4, the curve of the cumulative precipitation and potential evapotranspiration deviated in 1982, which also verified the reliability of the division for the baseline and modified period. The relationship in the baseline period was $\sum Q=0.34 *$ $\sum P+320.77$, which was applied to simulate the runoff in the modified period. In the double mass curve method, the results showed that human activities changed the runoff by $41.7 \mathrm{~mm}$ in the Taihu Lake Basin and contributed to $89 \%$ of the total runoff variation; climate changes contributed to $11 \%$ of the variation.

For the hydrological sensitivity method, the parameter $n$ was set to 0.5 [22]; then, $\beta$ and $\gamma$ were computed as 0.80 and -0.46 , respectively; $8.2 \mathrm{~mm}$ of the runoff variation was induced by climate changes. Consequently, the influences of the climate changes and human activities accounted for $18 \%$

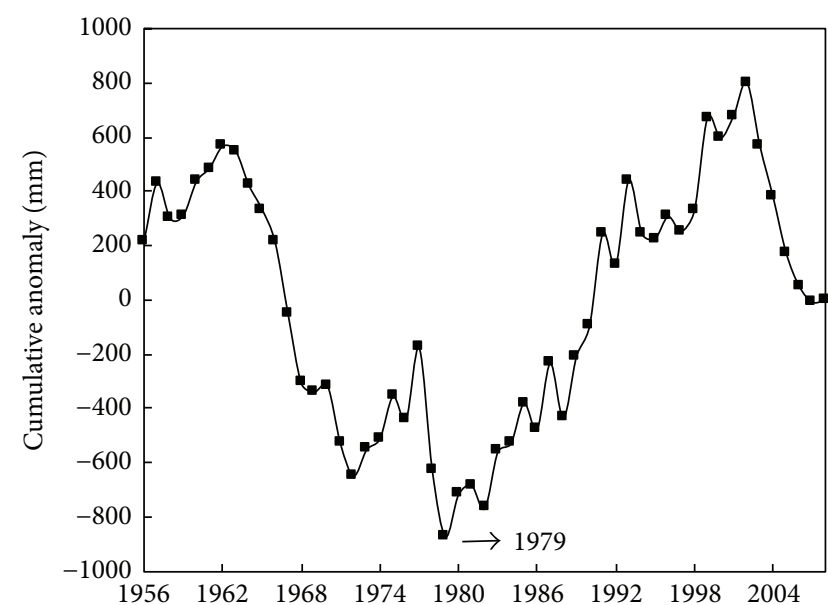

(a) Cumulative departure curve

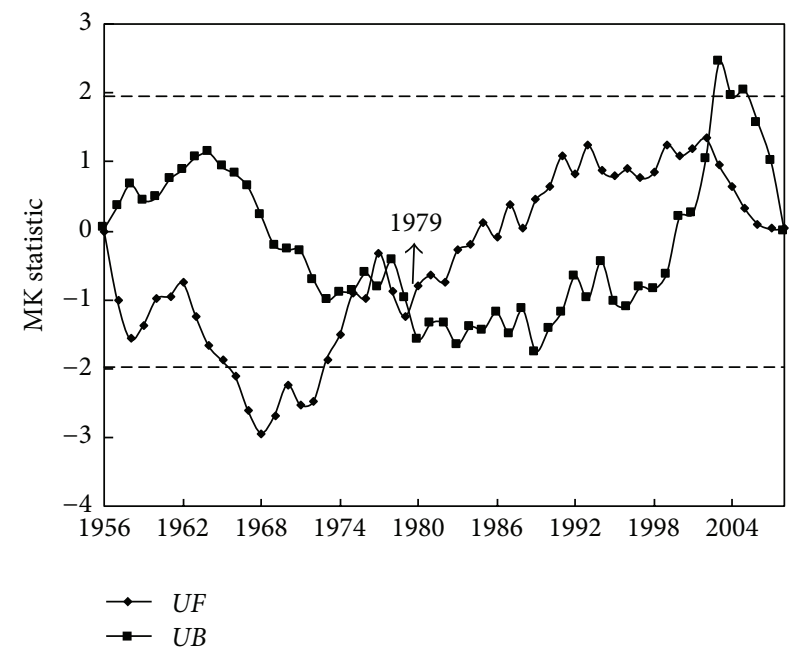

(b) Mann-Kendall test

FIGURE 2: Turning points of precipitation.

and $82 \%$, respectively, of the total runoff variation (Table 2). The error in the estimations by the double mass curve method and hydrological sensitivity method was $3.2 \mathrm{~mm}$, with a deviation of $7 \%$. Because of the relatively small error, the estimations could be used to verify the results. Therefore, $11 \sim 18 \%$ and $82 \sim 89 \%$ of the runoff variation were attributed to impacts of climate changes and human activities, respectively.

Previous studies reported that human activities played a slightly dominant role upstream of the Taihu Lake Basin and Xitiaoxi River Basin [13, 25]. In this study, the results showed that human activities played an absolutely dominant role in the runoff variation in the Taihu Lake Basin. Specifically, the urbanization increased the water stage, and the hydrological processes significantly responded to the change in the land use/cover in the basin [14]. The river system was disrupted by intense human activities, and many hydraulic projects were constructed. Climate factors such as ENSO played a role in the precipitation in the basin. Moreover, the instability of the climate variability increases the flooding and rainfall in the basin [24]. 
TABLE 2: Assessment of climate changes and human activities that impact the runoff variation in the Taihu Lake Basin.

\begin{tabular}{lcccc}
\hline Methods & $\begin{array}{c}\text { Runoff variation } \\
\text { induced by climate } \\
\text { changes } \\
(\mathrm{mm})\end{array}$ & $\begin{array}{c}\text { Contribution of } \\
\text { climate changes } \\
(\%)\end{array}$ & $\begin{array}{c}\text { Runoff variation } \\
\text { induced by human } \\
\text { activities } \\
(\mathrm{mm})\end{array}$ & $\begin{array}{c}\text { Contribution of } \\
\text { human activities } \\
(\%)\end{array}$ \\
\hline Double mass curve method & 5.0 & 11 & 41.7 & 89 \\
Hydrological sensitivity method & 8.2 & 18 & 38.5 & 82 \\
\hline
\end{tabular}

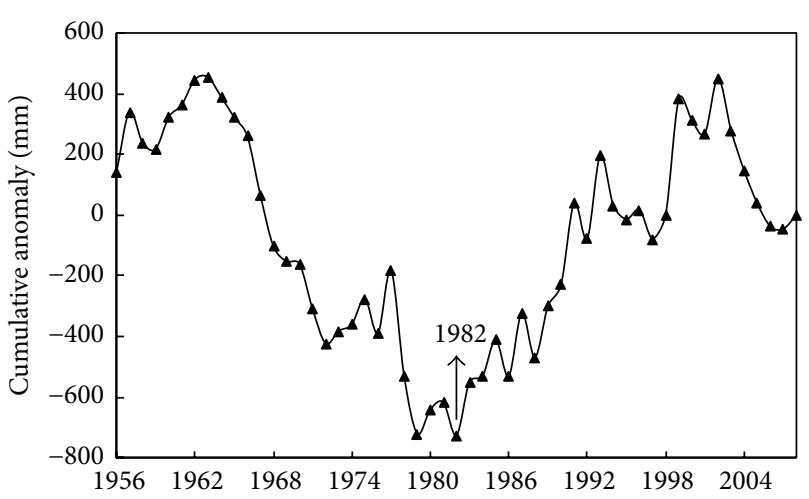

(a) Cumulative departure curve

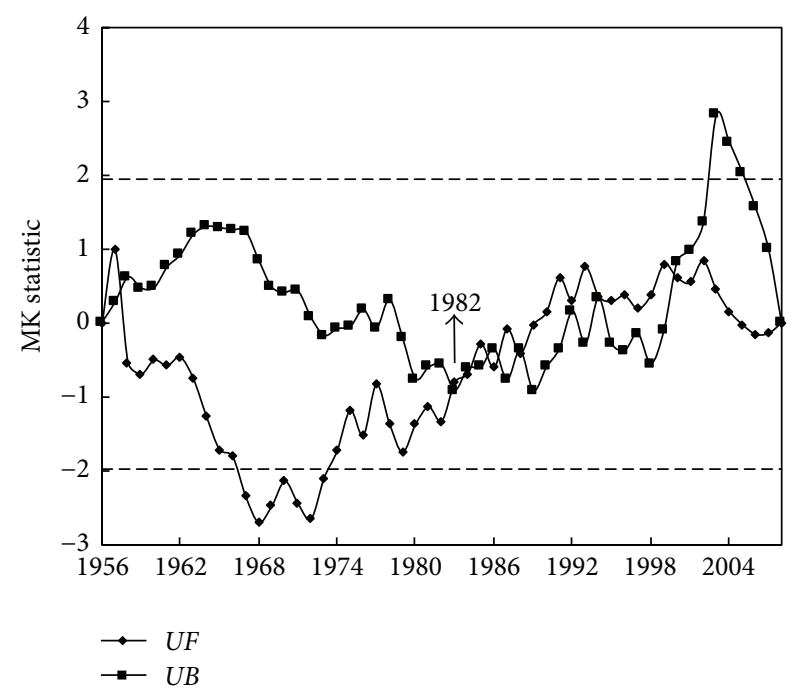

(b) Mann-Kendall test

FIgURE 3: Turning points of runoff.

The precipitation in HPJZ, HJHZ, WYZ, and HTZ during the modified period increased by $7.9 \%, 6.4 \%, 5.2 \%$, and $2.3 \%$, respectively, compared with the baseline period. The potential evapotranspiration changed the most in HPJZ (16.8\%); in the other three zones, the change was approximately $12 \%$. The runoff variation in HPJZ, WYZ, and HJHZ was $30.1 \%$, $27.8 \%$, and $20.2 \%$, respectively, but it only varied by $1.3 \%$ in HTZ (Figure 5). The relationship between the cumulative precipitation and runoff in the baseline period is shown in Table 3. In HTZ, HJHZ, HPJZ, and WYZ, human activities contributed to $76 \sim 79 \%, 83 \sim 84 \%, 84 \sim 92 \%$, and $95 \sim 97 \%$,

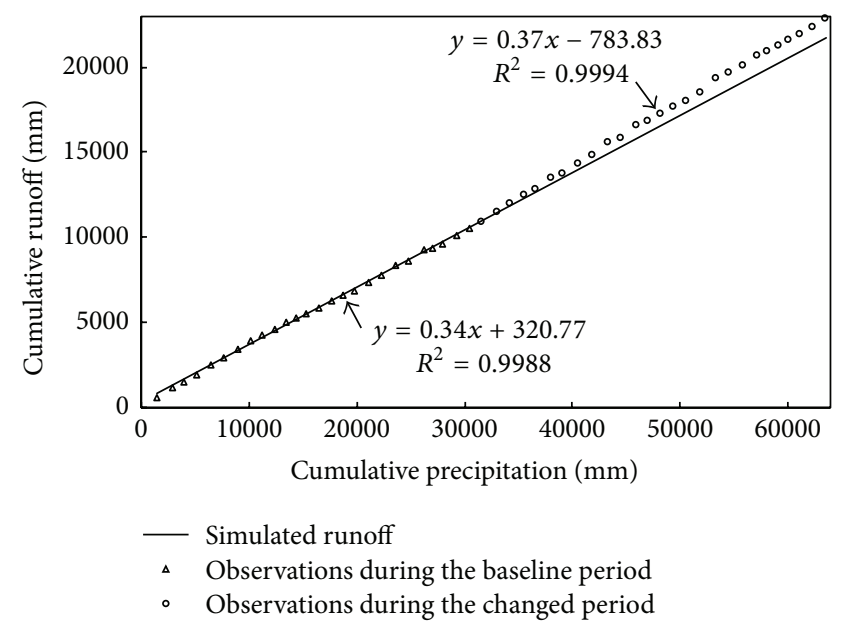

FIgUre 4: The double mass curve of precipitation and runoff in the Taihu Lake Basin.

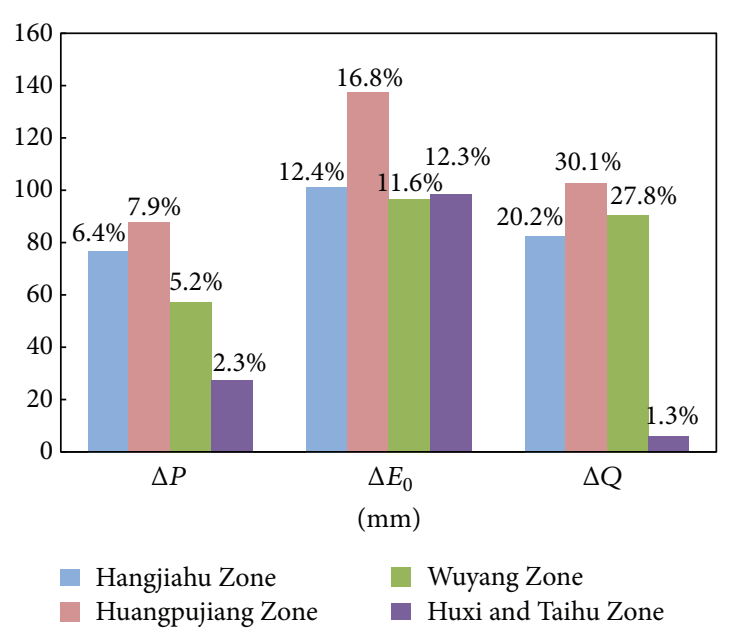

FIGURE 5: The changes in the hydrological variables in the four zones.

respectively, of the runoff variation. The impact of climate changes in the four zones was less than 24\% (Figure 6).

In the four zones, human interferences remarkably dominated the runoff variation. Human activities in WYZ were most intense, with an impact greater than 95\%; the lowest impact occurred in HTZ. The relationship between runoff and precipitation was closer in HTZ than in other three regions (Table 3 ). The largest coefficient of the double mass curve method and the hydrological sensitivity method 
TABLE 3: The relationship between the cumulative precipitation and runoff according to the two methods in the four zones.

\begin{tabular}{lcc}
\hline Zone & Equations of the double mass curve method & Equations of the hydrological sensitivity method \\
\hline Hangjiahu Zone & $\sum Q=0.33 * \sum P+323.3$ & $\Delta Q=0.81 * \Delta P-0.47 * \Delta E_{0}$ \\
Huangpujiang Zone & $\sum Q=0.30 * \sum P+250.2$ & $\Delta Q=0.79 * \Delta P-0.44 * \Delta E_{0}$ \\
Wuyang Zone & $\sum Q=0.29 * \sum P+296.1$ & $\Delta Q=0.78 * \Delta P-0.43 * \Delta E_{0}$ \\
Huxi and Taihu Zone & $\sum Q=0.37 * \sum P+358.6$ & $\Delta Q=0.88 * \Delta P-0.23 * \Delta E_{0}$ \\
\hline
\end{tabular}

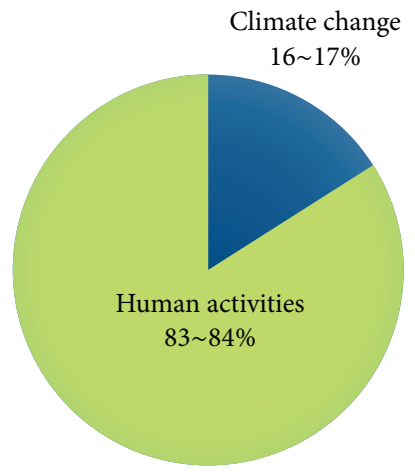

(a) Hangjiahu Zone

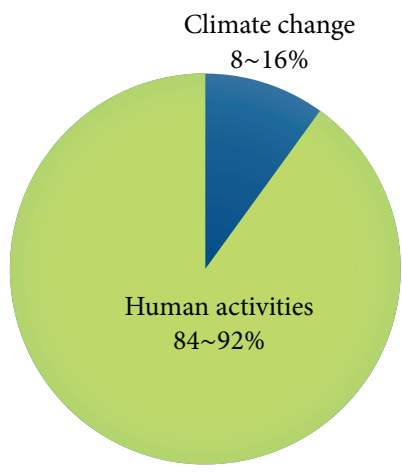

(b) Huangpujiang Zone

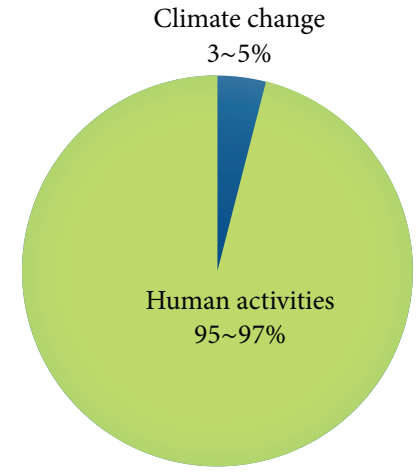

(c) Wuyang Zone

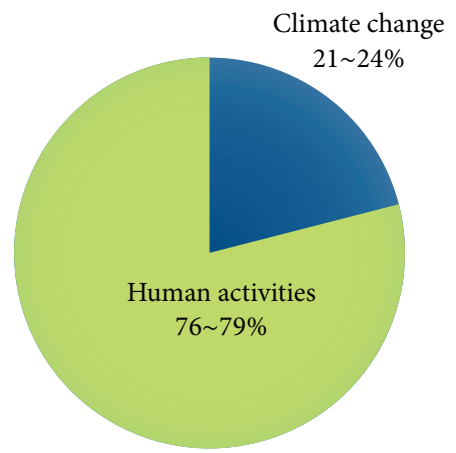

(d) Huxi and Taihu Zone

FIGURE 6: Quantitative assessments of the attribution to runoff variations in the four zones.

occurred in HTZ, while the smallest values occurred in WYZ. In fact, the main land cover was water bodies in HTZ, where the urbanization was weakest. However, WYZ had the most intense urbanization [26], which corresponded to the greatest human activities.

The limitations of this study include uncertainties and the simple hypothesis of an independent relation between climate changes and human activities. The general impacts of climate changes and human activities were assessed. The specific driving forces that impact the runoff variation will be analyzed in the future.

\section{Conclusion}

The Taihu Lake Basin suffers disturbances from climate changes and human activities. The detection and identification of runoff variations are significant for countering water resources issues in the basin. The study aims to quantify the driving forces of runoff variations in the Taihu Lake Basin. The conclusions can be summarized as follows:

(1) Based on the cumulative departure method and Mann-Kendall method, the runoff in the Taihu Lake Basin abruptly changed in 1982 . Thus, 1982 was considered the turning point between the baseline period (1956 1981) and the modified period (1982 2008).

(2) The impacts of climate changes and human activities were estimated by the double mass curve method and the hydrological sensitivity method; these factors contributed to $11 \sim 18 \%$ and $82 \sim 89 \%$, respectively, of the runoff variation in the basin. Human activities significantly dominated in the four zones, among which WYZ had the most intense human activities
(95 97\% contribution rate). The intense urbanization and remarkable land use/cover change in the Taihu Lake Basin could be the main human activities that contribute to hydrological alterations.

\section{Conflict of Interests}

The authors declare that there is no conflict of interests regarding the publication of this paper.

\section{Acknowledgments}

The authors would like to thank Mrs. Hejuan Lin of the Taihu Basin Authority, Ministry of Water Resources, China, for her advice and assistance with the data. This study is financially supported by the Key Technologies R \& D Program of China (Grant No. 2012BAC21B02).

\section{References}

[1] S. A. Changnon and M. Demissie, "Detection of changes in streamflow and floods resulting from climate fluctuations and land use-drainage changes," Climatic Change, vol. 32, no. 4, pp. 411-421, 1996.

[2] V. Ramanathan, P. J. Crutzen, J. T. Kiehl, and D. Rosenfeld, "Atmosphere: aerosols, climate, and the hydrological cycle," Science, vol. 294, no. 5549, pp. 2119-2124, 2001.

[3] P. C. D. Milly, R. T. Wetherald, K. A. Dunne, and T. L. Delworth, "Increasing risk of great floods in a changing climate," Nature, vol. 415, no. 6871, pp. 514-517, 2002.

[4] R. DeFries and K. N. Eshleman, "Land-use change and hydrologic processes: a major focus for the future," Hydrological Processes, vol. 18, no. 11, pp. 2183-2186, 2004. 
[5] D. Raje and P. P. Mujumdar, "Reservoir performance under uncertainty in hydrologic impacts of climate change," Advances in Water Resources, vol. 33, no. 3, pp. 312-326, 2010.

[6] K. H. Costigan and M. D. Daniels, "Damming the prairie: human alteration of Great Plains river regimes," Journal of Hydrology, vol. 444-445, pp. 90-99, 2012.

[7] T. Nakayama, "Impact of anthropogenic activity on ecohydrological process in continental scales," Procedia Environmental Sciences, vol. 13, pp. 87-94, 2012.

[8] T. Kiss and V. Blanka, "River channel response to climateand human-induced hydrological changes: case study on the meandering Hernád River, Hungary," Geomorphology, vol. 175176, pp. 115-125, 2012.

[9] L. Collet, D. Ruelland, V. Borrell-Estupina, and E. Servat, "Assessing the long-term impact of climatic variability and human activities on the water resources of a meso-scale Mediterranean catchment," Hydrological Sciences Journal, vol. 59, no. 8, pp. 1457-1469, 2014.

[10] F. Li, G. Zhang, and Y. J. Xu, "Separating the impacts of climate variation and human activities on runoff in the Songhua River Basin, Northeast China," Water, vol. 6, no. 11, pp. 3320-3338, 2014.

[11] J. Wang, H. Ishidaira, and Z. X. Xu, "Effects of climate change and human activities on inflow into the Hoabinh Reservoir in the Red River basin," Procedia Environmental Sciences, vol. 13, pp. 1688-1698, 2012.

[12] D. Pavanelli and A. Capra, "Climate change and human impacts on hydroclimatic variability in the Reno River catchment, Northern Italy," CLEAN-Soil, Air, Water, vol. 42, no. 5, pp. 535$545,2014$.

[13] L. H. Qiu, D. Z. Peng, J. Fang, and Z. Y. Zhang, "Estimation of hydrological responses to climate changes and human activities in the Xitiaoxi River basin," in Proceedings of the 3rd IMA International Conference on Flood Risk, Swansea, UK, March 2015.

[14] C. F. Zeng and L. C. Wang, "A study of hydrologic responses to land use and cover change in Taihu Lake Basin, Southeast China," Journal of Food, Agriculture and Environment, vol. 10, no. 3-4, pp. 1404-1408, 2012.

[15] R. G. Allen, L. S. Pereira, D. Raes, and M. Smith, FAO Irrigation and Drainage Paper no. 56, FAO, Rome, Italy, 2006.

[16] H. B. Mann, "Nonparametric tests against trend," Econometrica, vol. 13, pp. 245-259, 1945.

[17] M. G. Kendall, Rank Correlation Measures, Charles Griffin, London, UK, 1975.

[18] D. Z. Peng and Z. X. Xu, "Simulating the Impact of climate change on streamflow in the Tarim River basin by using a modified semi-distributed monthly water balance model," Hydrological Processes, vol. 24, no. 2, pp. 209-216, 2010.

[19] J. K. Searcy and C. H. Hardison, "Double mass curves," US Geological Survey Water-Supply Paper 1541-B, US Government Printing Office, Washington, DC, USA, 1960.

[20] J. C. I. Dooge, M. Bruen, and B. Parmentier, "A simple model for estimating the sensitivity of runoff to long-term changes in precipitation without a change in vegetation," Advances in Water Resources, vol. 23, no. 2, pp. 153-163, 1999.

[21] L.-J. Li, L. Zhang, H. Wang et al., "Assessing the impact of climate variability and human activities on streamflow from the Wuding River basin in China," Hydrological Processes, vol. 21, no. 25, pp. 3485-3491, 2007.
[22] H. Yang, D. Yang, Z. Lei, and F. Sun, "New analytical derivation of the mean annual water-energy balance equation," Water Resources Research, vol. 44, no. 3, Article ID W03410, 2008.

[23] P. C. D. Milly and K. A. Dunne, "Macroscale water fluxes 2. Water and energy supply control of their interannual variability," Water Resources Research, vol. 38, no. 10, pp. 24.1-24.9, 2002.

[24] Y. Yin, Y. Xu, and Y. Chen, "Relationship between flood/drought disasters and ENSO from 1857 to 2003 in the Taihu Lake basin, China," Quaternary International, vol. 208, no. 1-2, pp. 93-101, 2009.

[25] C. Zhang, B. Zhang, W. Li, and M. Liu, "Response of streamflow to climate change and human activity in Xitiaoxi river basin in China," Hydrological Processes, vol. 28, no. 1, pp. 43-50, 2014.

[26] J. Rong, C. F. Zeng, and L. C. Wang, "The impact of land use/cover change on hydrological processes of Lake Taihu basin," Journal of Lake Sciences, vol. 26, no. 2, pp. 305-312, 2014. 


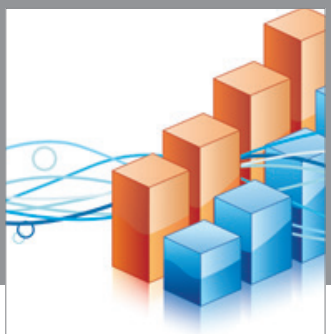

Advances in

Operations Research

vatem alat4

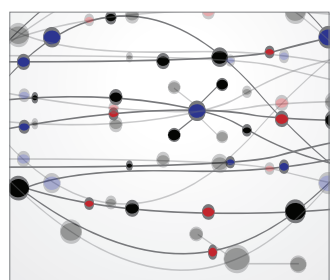

\section{The Scientific} World Journal
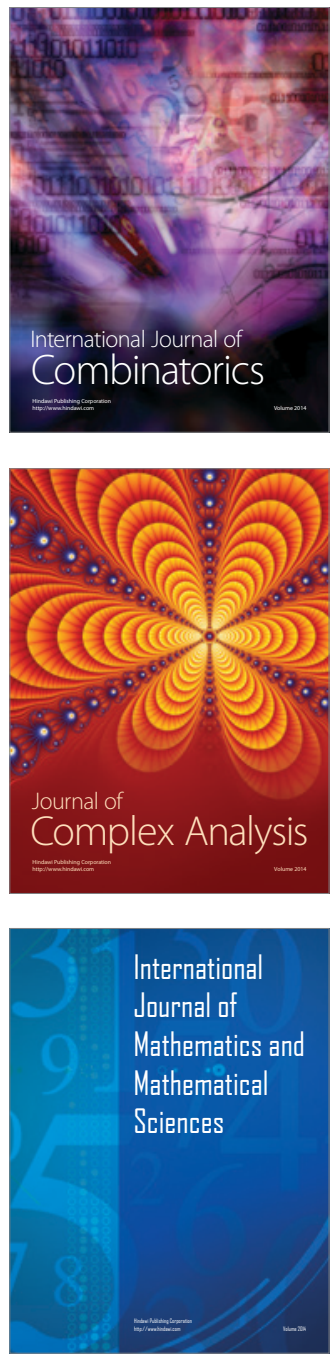
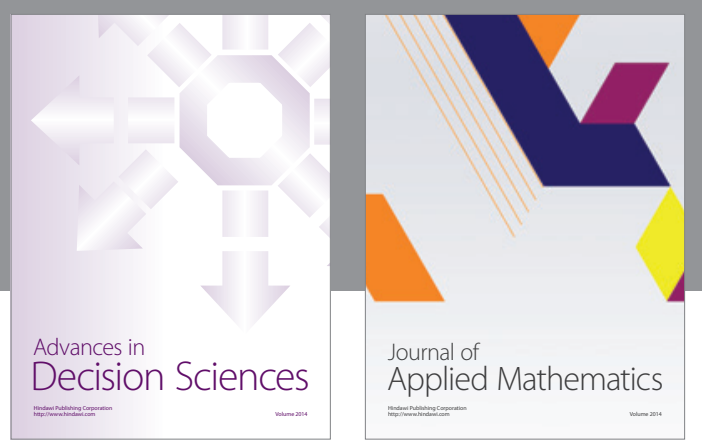

Algebra

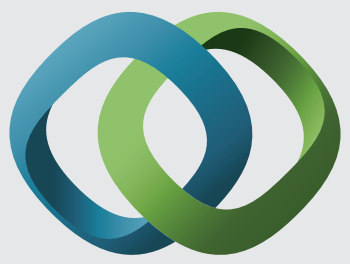

\section{Hindawi}

Submit your manuscripts at

http://www.hindawi.com
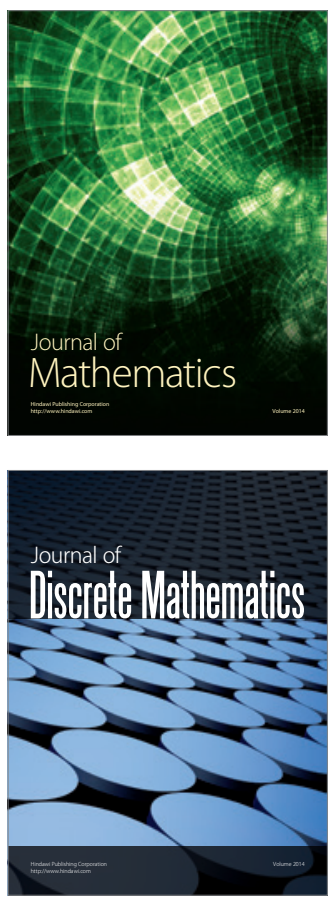

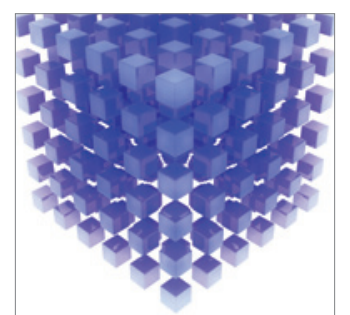

Mathematical Problems in Engineering
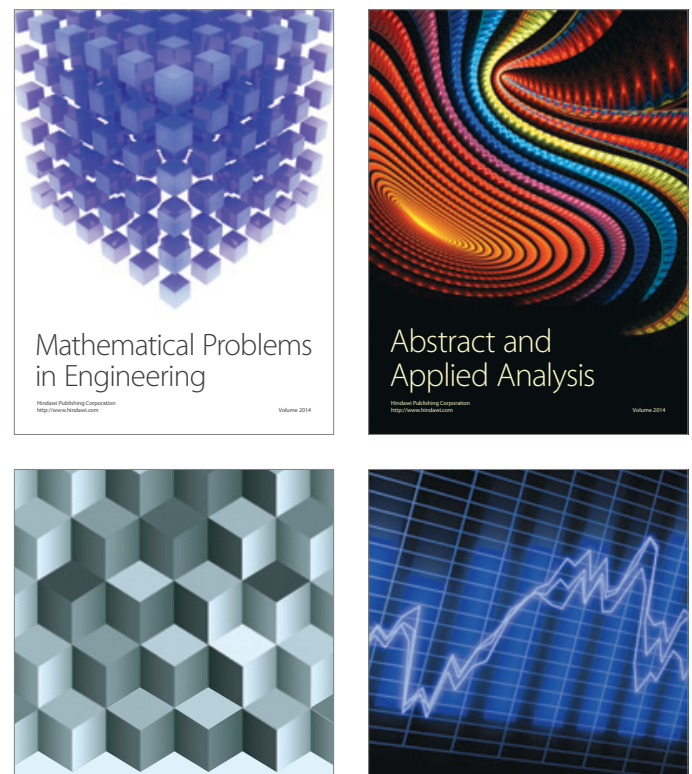

Journal of

Function Spaces

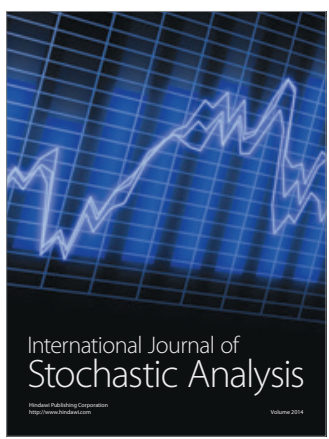

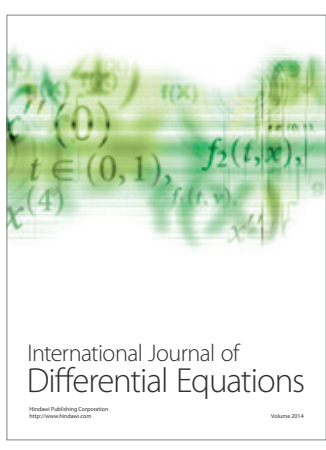
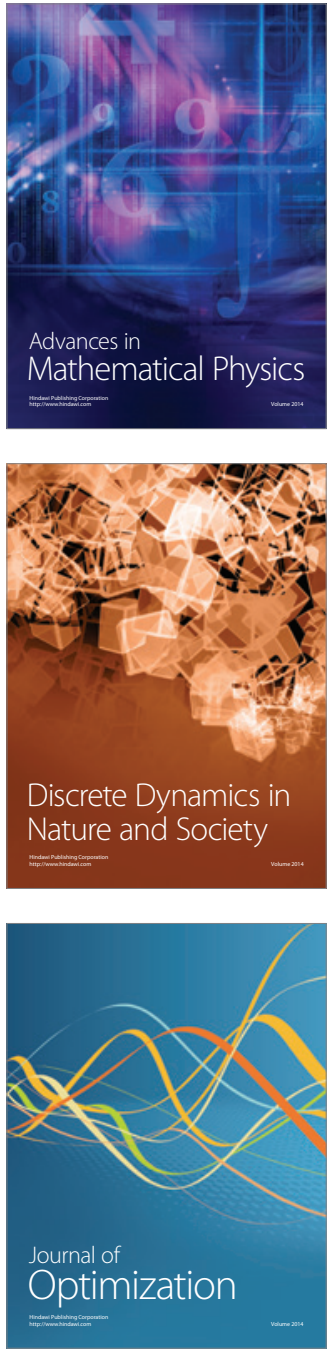